\section{Incidence of parasitoids and predators on eggs of seven species of Therididae (Araneae)}

\author{
Emilia Triana, Gilbert Barrantes* and Paul Hanson \\ Escuela de Biología, Universidad de Costa Rica, \\ Ciudad Universitaria, Rodrigo Facio, \\ San José, CP 2060, Costa Rica \\ *corresponding author, email: gilbert.barrantes@gmail.com
}

\section{Summary}

\begin{abstract}
Although many characteristics of the egg sacs of spiders likely evolved to reduce the effect of parasites and predators that attack their eggs, many parasite and predator insects have become specialized on spider eggs. Eggs of six of the seven species of Theridiidae included in this study were attacked by wasp parasites (Baeus achaearaneus, Idris sp., and Comastichus zopheros), and two by the specialized spider egg predator (Neuroptera: Zeugomantispa minuta). The incidence of parasites in the egg sacs varied across species. Parasites attacked more than $60 \%$ of the egg sacs of Tidarren sisyphoides and Parasteatoda tepidariorum, but none of the sacs of Latrodectus geometricus. The incidence of parasites in the egg sacs was higher during the dry season for $T$. sisyphoides, and during the rainy season for $P$. tepidariorum. The proportion of the eggs parasitized per egg sac varied from $0.09( \pm 0.19)$ in Nesticodes rufipes to $0.50( \pm 0.46)$ in $T$. sisyphoides. Differences in the biology of parasites, as well as in the structure of spider webs and habitat preference of spiders, may influence the incidence of parasitism and proportion of eggs parasitized in each egg sac.
\end{abstract}

\section{Introduction}

Maternal care is widespread in spiders and extremely variable even between species in the same genus. Within maternal care, construction of an egg sac and its protection is common in most spiders (Gertsch 1949). The egg sacs provide embryos with more stable environmental conditions for their development (Hieber 1985; Hieber 1992a) and protect them against predators and parasitoids (Austin 1985; Hieber 1992a,b). The silk layers of the egg sac reduce thermal stress and maintain favourable humidity inside the egg sac because it reduces water loss and egg desiccation (Hieber 1985; Hieber 1992a). The silk layers also act as a barrier to prevent fungal invasion of eggs and embryos (Christenson \& Wenzl 1980), and reduce or prevent attacks from predators and parasitoids (Austin 1985; Hieber 1992a,b).

Spiders have evolved many different behaviours to reduce predation and parasitism on their eggs. For instance, Pozonia nigroventris and Micrathena spp. (Araneidae) lay their eggs on the surface of a dead leaf which the spider then folds, forming a protective case that it drops to the ground (Moya et al. 2010). Wolf spiders protect their eggs by constantly carrying the egg sac attached to their spinnerets until the spiderlings emerge (Edgar 1971; Cobb \& Cobb 2004). Some araneids build an egg sac and then use a thread to hang it from their web (Hieber 1992b). In the family Theridiidae, many species construct different types of retreats with silk, plant debris, remnants of prey, or folding a leaf that help camouflage the egg sacs (Nielsen 1932; Bristowe 1958; Barrantes \& Weng 2007).

Despite the protection that the egg sacs provide, many parasitoid and predatory insects are capable of gaining access to the eggs within the egg sac (Auten 1925; Austin 1985). Mantisflies (Mantispinae) are obligate predators of spider eggs during their larval stage. The larva burrows into the egg sac or enters the egg sac during its construction and then feeds on the spider's eggs (Redborg \& MacLeod 1985; Guarisco 1998). However, wasp and fly parasitoids are likely the major causes of destruction of spider eggs. Larvae of many of these parasitoids feed and develop exclusively within spider eggs (Auten 1925; Valerio 1971, 1975; Fitton, Shaw \& Austin 1987).

Of the 13 Hymenoptera families that include egg endoparasitoids in the Neotropics, six of them have species that 


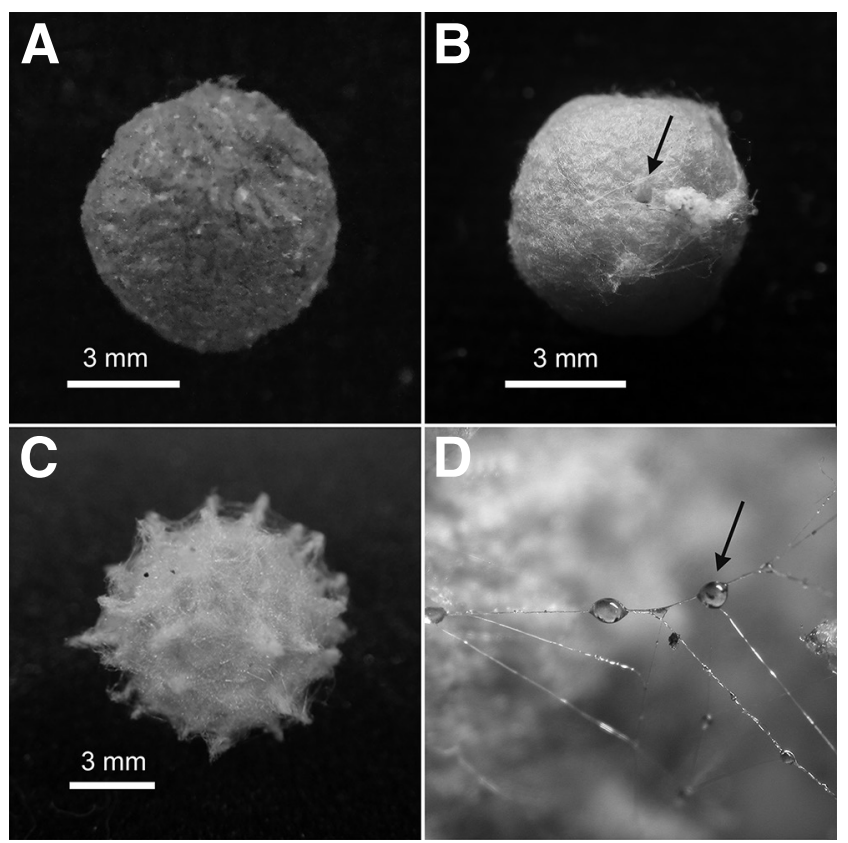

Fig. 1: Egg sacs of three species of Theridiidae. A Parasteatoda tepidariorum; $\mathbf{B}$ Tidarren sisyphoides, arrow points to the exit hole of spiderlings; C Latrodectus geometricus; $\mathbf{D}$ shows some sticky threads that $L$. geometricus attaches to the outer surface of the egg sac.

are specific to spider eggs: Scelionidae (Baeini); Eulophidae (some Entedonini and Tetrastichinae); Eupelmidae (some Eupelminae); Eurytomidae (just a few species; see Discussion); and Pteromalidae (Arachnopteromalus) (Hanson \& Gauld 2006). These highly specialized wasps insert their long ovipositor several times through both the silk layer and the wall of the egg and lay one of their own eggs, which develops into a larva that feeds on a spider egg (Austin 1985); or the female wasp enters the egg sac to oviposit directly in some of the spider's eggs (Baeus californicus, Pemberton \& Rosa 1940; Ceratobaeus spp., Austin 1984).

In this study, we recorded the egg parasitoids found in egg sacs of seven theridiid spiders: Tidarren sisyphoides (Walckenaer, 1841), Parasteatoda tepidariorum (C. L. Koch, 1841), Parasteatoda tesselata (Keyserling, 1884), Nesticodes rufipes (Lucas, 1846), Latrodectus geometricus C. L. Koch, 1841, Theridion evexum Keyserling, 1884, and Anelosimus studiosus (Hentz, 1850). We then quantified the proportion of egg sacs parasitized, the proportion of eggs parasitized in each sac, and the correlation of seasonal climatic changes on the incidence of egg sacs parasitized. The egg sacs of these species have a papery surface, except L. geometricus in which the egg sac surface is slightly translucent and studded with silk pompons (Fig. 1; Kaston 1970).

\section{Methods}

We collected a total of 144 egg sacs from seven species of Theridiidae on the campus of the University of Costa

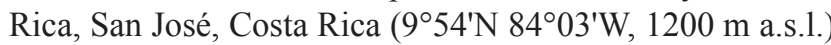
and some nearby areas from April 2007 to November 2009. The annual average temperature is around $20^{\circ} \mathrm{C}$, with a dry season from December through March. The site is urbanized with isolated patches of trees and gardens. All spider species are abundant and can be found on bushes or on external walls of buildings. For each species, we collected the following numbers of egg sacs: 47 Latrodectus geometricus, 40 Parasteatoda tepidariorum, 37 Tidarren sisyphoides, 8 P. tesselata, 7 N. rufipes, 4 Theridion evexum, and 1 Anelosimus studiosus. Vouchers have been deposited in the Museo de Zoología of the Universidad de Costa Rica.

Egg sacs were placed individually in a Petri dish in the laboratory at room temperature. When either spiderlings or parasitoids emerged, we removed them and left the egg sac in the Petri dish for two more weeks, waiting for other spiderlings or parasitoids to emerge. After this additional time, we opened the egg sac and examined its contents to check whether some spiderlings or wasps had failed to exit the egg sac. For wasps, we counted the total males and females to determine the sex ratio. If both parasitoids and spiderlings emerged, we determined the proportion of eggs parasitized within each egg sac. Total eggs for each egg sac was calculated as the sum of spiderlings, wasps, and unhatched eggs; if unhatched eggs had a dead wasp or wasp pupa inside they were considered as parasitized, otherwise they were considered as not parasitized.

Parasitoids were identified using keys provided in LaSalle (1994) and Margaría, Loiácono \& Gonzaga (2006), but for the identification of Idris (Scelionidae) species there are no keys presently available. All specimens obtained in this study belong to Idris sensu stricto, and not to Ceratobaeus, which is currently a synonym of Idris. While all our specimens appear to belong to a single species, it should be noted that there are an estimated 100 species of Idris sensu

\begin{tabular}{|c|c|c|c|c|c|}
\hline Spider & $N$ & $\begin{array}{l}\% \text { egg sacs } \\
\text { parasitized }\end{array}$ & $\begin{array}{c}\text { Wasps/total } \\
\text { eggs }\end{array}$ & $\begin{array}{l}\text { No. eggs per } \\
\text { sac }\end{array}$ & Parasitoid species \\
\hline Tidarren sisyphoides & 37 & 67 & $0.50(0.46)$ & $86.5(54.5)$ & $\begin{array}{l}\text { Baeus achaearaneus, Idris sp., Comastichus } \\
\text { zopheros }\end{array}$ \\
\hline Parasteatoda tepidariorum & 40 & 65 & $0.17(0.17)$ & $142.0(62.5)$ & $\begin{array}{l}\text { Baeus achaearaneus, Comastichus zopheros, } \\
\text { Zeugomantispa minuta }\end{array}$ \\
\hline Parasteatoda tesselata & 8 & 12.5 & $?$ & $?$ & Baeus achaearaneus, Idris sp. \\
\hline Nesticodes rufipes & 7 & 29 & $0.09(0.19)$ & $145.1(55.3)$ & Baeus achaearaneus \\
\hline Latrodectus geometricus & 47 & 2.12 & 0 & $141.9(62.4)$ & Zeugomantispa minuta \\
\hline Theridion evexum & 4 & 25 & $?$ & $?$ & Baeus achaearaneus \\
\hline Anelosimus studiosus & 1 & 100 & $?$ & $?$ & Idris sp. \\
\hline
\end{tabular}

Table 1: Percentage of egg sacs parasitized, proportion of eggs parasitized in each egg sac, number of eggs per sac, and parasitoid species collected from egg sacs of seven Theridiidae spiders. Standard deviation in parentheses. Zeugomantispa minuta, an egg predator, is also included. 

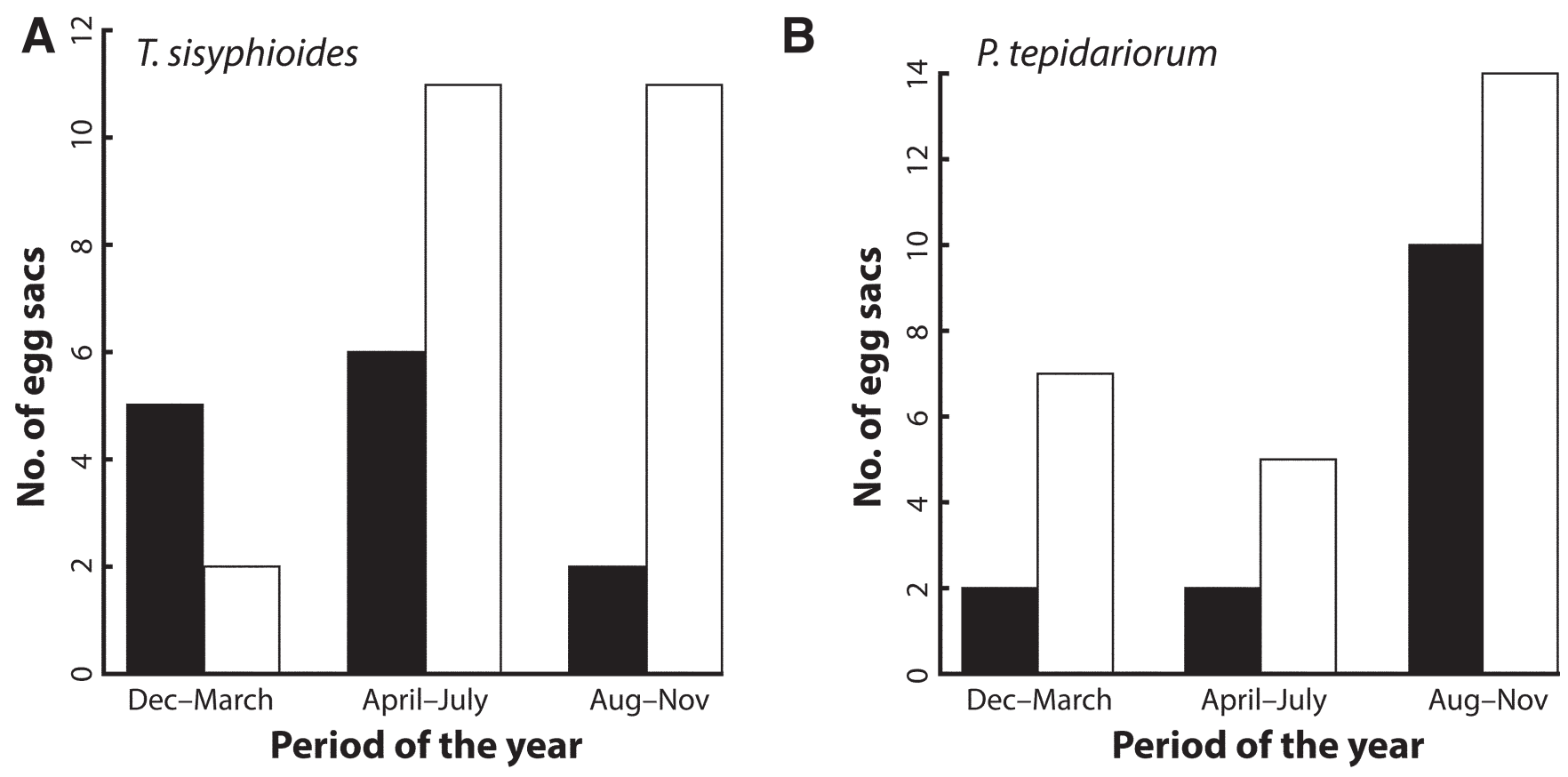

Fig. 2: Number of egg sacs of Tidarren sisyphoides (A) and Parasteatoda tepidariorum $(\mathbf{B})$, parasitized (black bars) and not parasitized (white bars) during three different seasons. December-March is the driest period of the year, August-November the rainiest, and April-July is a transitional period.

lato, in Costa Rica, most of which are undescribed (Masner 1995).

We divided the year into three periods according to the rainfall pattern: dry period, from December through March; transition period, from April through July; and rainy period, from August through November. We analysed the effect of seasonality on the incidence of parasitism of egg sacs and on the proportion of eggs parasitized within each egg sac for those spider species with more than 30 egg sacs, using chisquared, Kruskall-Wallis, and Mann-Whitney tests. We also examined the effect of the number of eggs in each egg sac and seasonality (and interaction of both factors) on the probability of an egg to be parasitized, using a generalized linear model (with binomial distribution). All statistical analyses were performed with R statistical Language (version 2.13.2: http://cran.r-project.org).

\section{Results}

Egg endoparasitism varied widely among the seven species of Theridiidae (Table 1). Tidarren sisyphoides was the species with the highest percentage (67\%) of egg sacs parasitized by wasps, while L. geometricus had none of their egg sacs parasitized (A. studiosus was not included in the analysis due to insufficient sample). Three different species
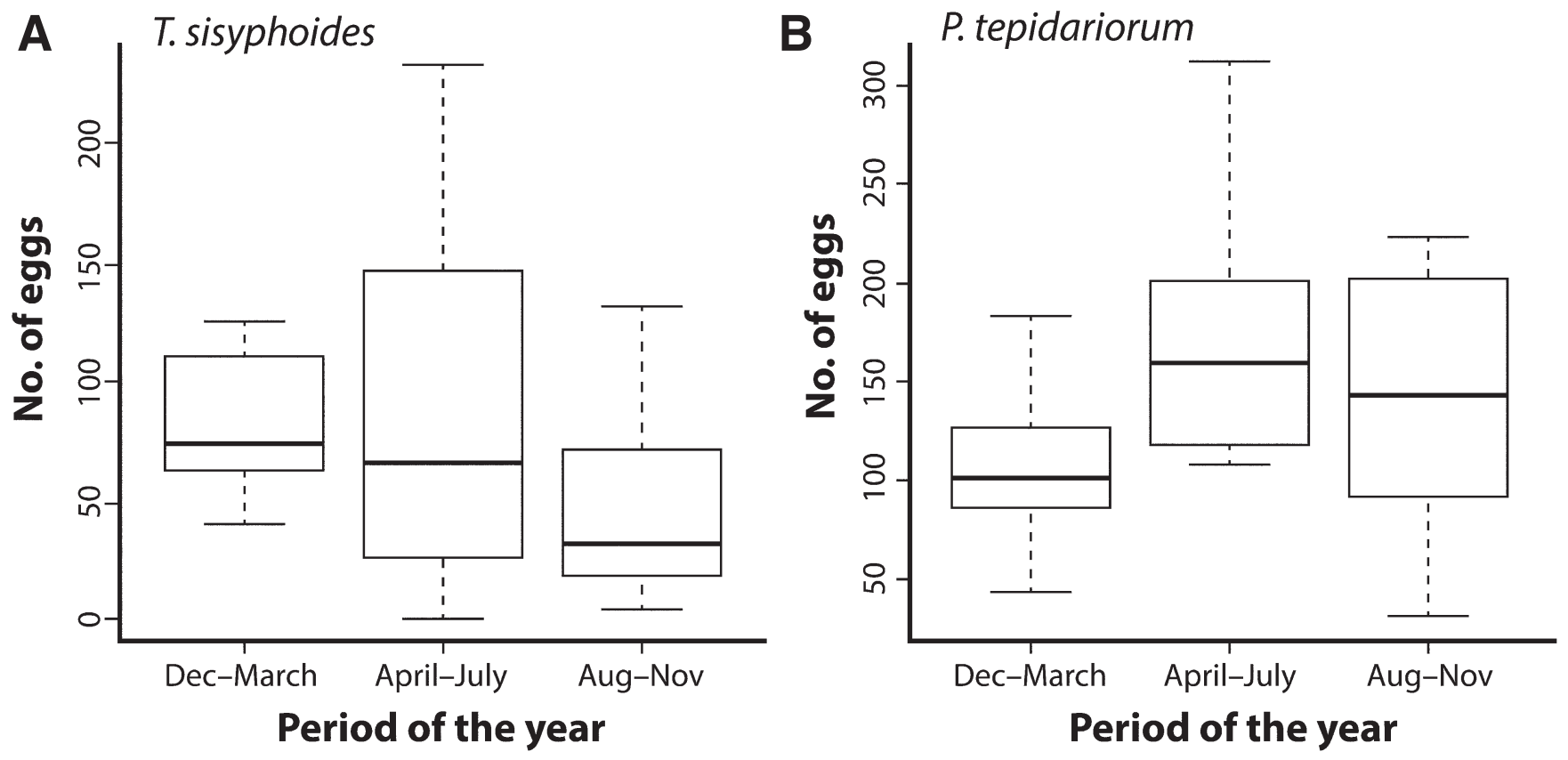

Fig. 3: Number of eggs per egg sac for Tidarren sisyphoides (A) and Parasteatoda tepidariorum (B) during three different seasons. December-March is the driest period of the year, August-November the rainiest, and April-July is a transitional period. 


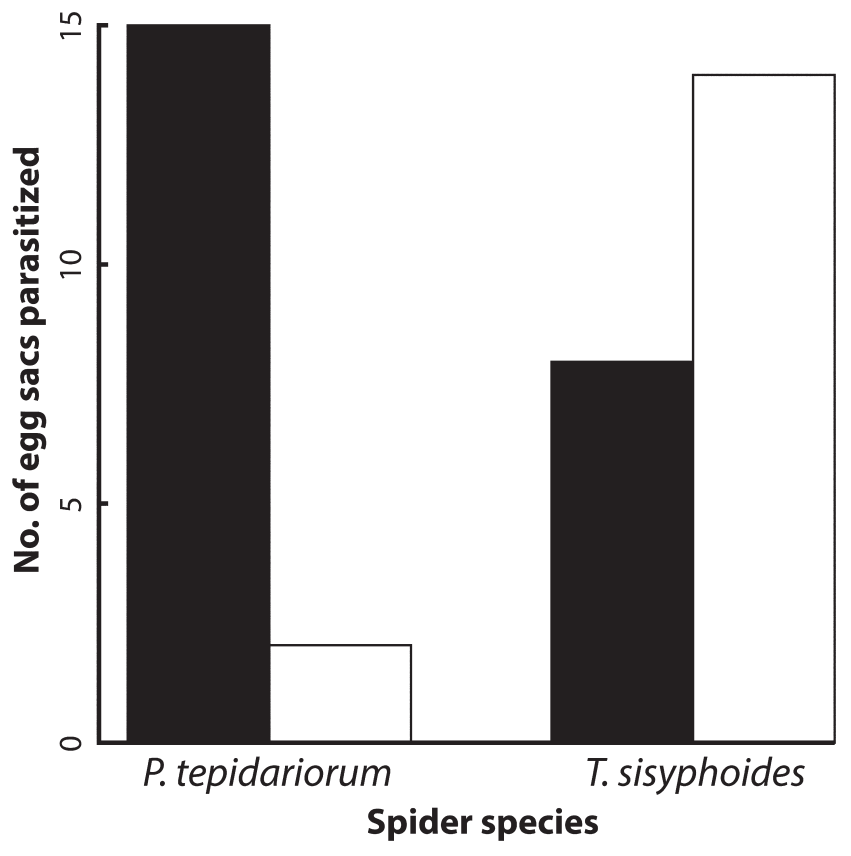

Fig. 4: Number of egg sacs of Parasteatoda tepidariorum and Tidarren sisyphoides parasitized by Baeus achaearaneus (black bars) and Comastichus zopheros (white bars).

of wasp (Scelionidae: Baeus achaearaneus, Idris sp.; and Eulophidae: Comastichus zopheros) and an egg predator (Mantispinae: Zeugomantispa minuta) emerged from egg sacs of the seven theridiids ( $N=144$ egg sacs). The most common parasitoid was Baeus achaearaneus, which was found in egg sacs of five spider species, Idris sp. in three species, and C. zopheros in two species (Table 1). The egg predator, Z. minuta, fed on eggs of two different spiders: $P$. tepidariorum and L. geometricus. On two occasions, two parasitoid species emerged from the same egg sac. From a single egg sac of $T$. sisyphoides and $P$. tesselata emerged C. zopheros and Idris sp., and Baeus achaearaneus and Idris sp., respectively. On one occasion, two groups of C. zopheros emerged from one egg sac of T. sisyphoides 16 days apart, suggesting that two different wasps laid eggs in the same spider sac.

Tidarren sisyphoides had a significantly larger proportion of egg sacs parasitized during the driest period of the year $\left(\chi^{2}=6.27, \mathrm{df}=2, P=0.043\right.$; Fig. 2A), whereas $P$. tepidariorum had a similar proportion of egg sacs parasitized in all three time-periods $\left(\chi^{2}=1.24\right.$, $\mathrm{df}=2, P=0.537$; Fig. 2B). T. sisyphoides also had a significantly larger proportion of eggs parasitized in their egg sacs than $P$. tepidariorum (Mann-Whitney test $=340, P=0.0013$; Table 1 ); other species were not included due to small sample size. For $P$. tepidariorum the proportion of eggs parasitized was significantly higher during the rainiest period of the year (KruskalWallis test $=8.43, P=0.015)$, but the proportion of eggs parasitized was similar during the three time periods for $T$. sisyphoides (Kruskal-Wallis test $=3.34, P=0.188$ ). The generalized linear model indicated that both the number of eggs per sac $(Z=-2.51, P=0.012)$ and the seasonal period $(\mathrm{Z}=2.09, P=0.037)$ were significantly associated with the probability that egg sacs of $T$. sisyphoides were parasitized: the probability that a wasp parasitized an egg sac increased as the number of eggs in the sac decreased, and that probability was significantly lower during the rainy season (Fig.
$3 \mathrm{~A})$; interaction between the two factors was not significant. For $P$. tepidariorum, the probability that a wasp parasitized an egg sac was significantly higher during the rainy season ( $\mathrm{Z}=2.28, P=0.027$; Fig. $2 \mathrm{~B}$ ), but the number of eggs per egg sac did not significantly affect this probability (Fig. 3B).

Baeus achaearaneus and Comastichus zopheros were the most common parasitoids in egg sacs of $P$. tepidariorum and T. sisyphoides. Baeus parasitized a larger number of egg sacs of $P$. tepidariorum than $C$. zopheros, while $C$. zopheros parasitized more egg sacs of $T$. sisyphoides than Baeus (Fig. 4). Idris sp. parasitized only one egg sac of $T$. sisyphoides but none of $P$. tepidariorum.

The sex ratio (males/total) of C. zopheros and Baeus that emerged from egg sacs of $P$. tepidariorum and $T$. sisyphoides was strongly female biased. The sex ratio for $C$. zopheros in egg sacs of $P$. tepidariorum was $0.13 \pm \mathrm{sd}$ $=0.13(N=13$, no. egg sacs $)$ and $0.09 \pm 0.04(N=2)$ in $T$. sisyphoides. Baeus had a similar sex ratio: $0.15 \pm 0.14(N=$ $15)$ in sacs of $P$. tepidariorum and $0.19 \pm 0.34(N=6)$ in egg sacs of $T$. sisyphoides.

\section{Discussion}

All wasp species in the tribe Baeni use spider eggs as a food source for their parasitic larvae (Steven \& Austin 2007). Within this tribe, wasps of the genera Baeus and Idris have a wide spectrum of host spider species in different families that vary in their life history strategies, from wandering spiders (e.g. Lycosidae) to web-building spiders (e.g. Araneidae and Theridiidae) (Austin 1985; Cobb \& Cobb 2004). In this study, the theridiids parasitized by Baeus also varied in habitat use and web design (Eberhard 1972; Barrantes \& Weng 2006, 2007; Eberhard, Agnarsson \& Levi 2008; Madrigal-Brenes \& Barrantes 2009). P. tepidariorum and $N$. rufipes are synanthropic species that construct isolated, three-dimensional, meshed webs outside and inside buildings; webs of these species are seldom found on structures other than buildings. T. sisyphoides build their domed-sheet webs on isolated treelets and bushes with rigid leaves for web building, primarily in open areas (Madrigal-Brenes $\&$ Barrantes 2009), and P. tesselata construct their sheet webs on similar plants, also in open areas, and often in colonies (Eberhard 1972; Barrantes \& Weng 2006). T. evexum construct their webs on undergrowth herbs and bushes of secondary and mature forests, and the webs consist of a retreat built by a folded leaf from which the spider lays straight sticky threads that it attaches mostly to leaves and twigs below the retreat (Barrantes \& Weng 2007).

Our results suggest that neither the web architecture nor the habitat used by spiders to build their webs hinder Baeus in gaining access to the spiders' eggs. Baeus attacked eggs of spiders with very different web design (e.g. P. tepidariorum versus $T$. sisyphoides) and contrasting habitats (e.g. $P$. tepidariorum versus $T$. evexum). It has been suggested that these tiny wasps rely on airborne and chemical signals to locate their host eggs (Austin, Johnson \& Dowton 2005). However, information on the mechanisms used by the tiny wingless Baeus females to move across complex landscapes (e.g. understory of secondary and mature forests) are 
unknown. Idris parasitized eggs of the three spider species that built sheet webs in open areas.

Comastichus zopheros and Baeus parasitized eggs of $P$. tepidariorum and T. sisyphoides, species with different web architecture but similar habitat preference. C. zopheros was previously reported from $T$. sisyphoides (Knoflach \& van Harten 2006), but this is the first report of Baeus for this spider. We found C. zopheros in two egg sacs of $P$. tepidariorum, but $T$. sisyphoides was its most common host (Fig. 4). Valerio (1971) reported Baeus achaearaneus as the only egg parasitoid of $P$. tepidariorum in the same locality (the parasitoid was cited as Baeus sp. but Valerio's specimens were subsequently described by Loiácono 1973 as B. achaearaneus). The high occurrence of $C$. zopheros in egg sacs of $T$. sisyphoides may be the result of a preference of this parasitoid for T. sisyphoides or, alternatively, it is possible that the anthropogenic habitat used by $P$. tepidariorum makes it difficult for the parasitoid to locate this spider.

Parasitoids were present in egg sacs of $T$. sisyphoides and $P$. tepidariorum during all three time periods. The occurrence of parasitoids year round may be related to the year-round presence of host spiders and egg sacs. A similar pattern was found for koinobiont spider parasitoids of other spider species in the same study area (Barrantes, Eberhard $\&$ Weng 2008). The seasonal changes in the incidence of parasitoids in the egg sacs of these two spider species is more difficult to explain. This, however, may be the effect of changes in abundance and distribution of either hosts, parasitoids or both, but this result may also be affected by the relatively small sample size included in the analysis.

The proportion of eggs parasitized in each egg sac was higher for $T$. sisyphoides than in $P$. tepidariorum. This may be related to the flying capacity of female $C$. zopheros which allows more females to gain access to the egg sacs (see Results). Another possibility is that females of C. zopheros carry a larger number of eggs than the wingless females of Baeus, the main parasitoid of P. tepidariorum (but information on number of eggs that females of these species carry are lacking).

It is very surprising that parasitoid wasps, including the apparently extreme generalist Baeus, did not attack eggs of L. geometricus. Only the egg predator, Z. minuta (Peny \& da Costa, 1983), emerged from a single egg sac. It is possible that the structure of the adult web, which consists of a dense-walled silk retreat constructed in a sheltered place from which a sloping sheet extends forward with gumfoot lines extending from the border of the sheet to the ground below (see Eberhard, Barrantes \& Madrigal-Brenes 2008 for a detailed description of the web), limits the attack of parasitoids on L. geometricus eggs. Adult females of $L$. geometricus produce and maintain the egg sacs within the dense silken retreat and the spiders also add sticky threads to the external wall of some of their egg sacs (Fig. 1), which may prevent Baeus and other wasp parasitoids from gaining access to the eggs inside the sac. However, in various parts of the world, including the Neotropics, the eggs of L. geometricus are often parasitized by certain species of Eurytomidae; these species were previously placed in Desantisca, then in Eurytoma (e.g. in Hanson \& Gauld 2006), but are now placed in Philolema (Lotfalizadeh, Delvare \& Rasplus 2007). Parasitoids in this genus have also been found in egg sacs of L. geometricus in Costa Rica, but not in this study (PH unpublished data).

For successful development of a parasitoid larva inside a spider egg, wasp oviposition should occur within the first days after the spider has laid her eggs (Austin 1984). This short window of time likely reduces the number of parasitoid females that can gain access to a single spider egg sac, and female biased sex ratios are to be expected in haplodiploid insects in which siblings emerge in proximity (Hamilton 1967).

Our results provide information on new host spiders parasitized by Baeus achaearaneus, Idris, and Comastichus zopheros, and on web and habitat features of the hosts that seem to correlate with parasitoid species preferences. It is also notable that much more information on natural history and behaviour of the wasp parasitoids (e.g. how the wingless females of Baeus locate and access their host webs) is required to fully understand the impact of egg parasitoids on their spider hosts.

\section{Acknowledgements}

We thank two anonymous reviewers for valuable comments on a previous version of the manuscript and Angel Solís for the identification of the Mantispidae species. We received financial support from the Vicerrectoría de Investigación, Universidad de Costa Rica.

\section{References}

AUSTIN, A. D. 1984: The fecundity, development and host relationships of Ceratobaeus spp. (Hymenoptera: Scelionidae), parasites of spider eggs. Ecological Entomology 9: 125-138.

AUSTIN, A. D. 1985: The function of spider egg sacs in relation to parasitoids and predators, with special reference to the Australian fauna. Journal of Natural History 19: 359-376.

AUSTIN, A. D., JOHNSON, N. F. \& DOWTON M. 2005: Systematics, evolution, and biology of scelionid and platygastrid wasps. Annual Review of Entomology 50: 553-82.

AUTEN, M. 1925: Insects associated with spider nests. Contribution from Department of Zoology and Entomology of Ohio State University 80: $240-250$.

BARRANTES, G. \& WENG, J. 2006: The attack behaviour of Achaearanea tesselata (Araneae: Theridiidae). Journal of Arachnology 34: 456466.

BARRANTES, G. \& WENG, J. 2007: Natural history, feeding behaviour, and parasites of Theridion evexum (Araneae: Theridiidae). Bulletin of the British Arachnological Society 14: 61-65.

BARRANTES, G., EBERHARD, W. G. \& WENG, J. 2008: Seasonal patterns of parasitism of the tropical spiders Theridion evexum (Araneae, Theridiidae) and Allocyclosa bifurca (Araneae, Araneidae) by the wasps Zatypota petronae and Polysphincta gutfreundi (Hymenoptera, Ichneumonidae). Revista Biologia Tropical 56: 749-754.

BRISTOWE, W. S. 1958: The world of spiders. London, Collins.

CHRISTENSON, T. E \& WENZL, P. A. 1980: Egg laying of the Golden Silk Spider, Nephila clavipes L. (Araneae: Araneidae): functional analysis of the egg sac. Animal Behaviour 28:1110-1118.

COBB, L. M. \& COBB, V. A. 2004: Occurrence of parasitoid wasps, Baeus sp. and Gelis sp., in the egg sacs of the wolf spiders, Pardosa moesta and Pardosa sternalis (Araneae, Lycosidae) in southeastern Idaho. The Canadian Field-Naturalist 118: 121-123.

EBERHARD, W. G. 1972: Observations on the biology of Achaearanea tesselata (Araneae: Theridiidae). Psyche 79: 209-212. 
EBERHARD, W. G., AGNARSSON, I. \& LEVI, H. W. 2008: Web forms and the phylogeny of theridiid spiders (Araneae: Theridiidae): chaos from order. Systematics and Biodiversity 6: 415-475.

EBERHARD, W. G., BARRANTES, G. \& MADRIGAL-BRENES, R. 2008: Vestiges of an orb-weaving ancestor? The "biogenic law" and ontogenetic changes in the webs and building behaviour of the black widow spider Latrodectus geometricus (Araneae: Theridiidae). Ethology Ecology and Evolution 20: 211-244.

EDGAR, W. D. 1971: Aspects of the ecology and energetics of the egg sac parasites of the Wolf Spider Pardosa lugubris (Walckenaer). Oecologia 7: 155-163.

FITTON M. G., SHAW, M. R. \& AUSTIN, A. D. 1987: The Hymenoptera associated with spiders in Europe. Zoological Journal of the Linnean Society 90: 65-93.

GERTSCH, W. J. 1949: American spiders. Princeton, NJ, Van Nostrand.

GUARISCO, H. 1998: First observation of egg sac predation of the Mantisfly, Mantispa interrupta (Neuroptera, Mantispidae) upon the Wolf Spider, Gladicosa gulosa (Araneae, Lycosidae). Kansas Academy of Science 101: 60-62.

HAMILTON, W. D. 1967: Extraordinary sex ratios. Science 156: $477-$ 488.

HANSON P. E. \& GAULD, I. D. 2006: Hymenoptera de la Región Neotropical. Memoirs of the American Entomological Institute, Gainesville 77, 994 pp.

HIEBER, C. S. 1985: The "insulation" layer in the cocoons of Argiope aurantia (Araneidae: Araneae). Journal of Thermal Biology 10: 171-175.

HIEBER, C. S. 1992a: The role of spider cocoons in controlling desiccation. Oecologia 89: 442-448.

HIEBER, C. S. 1992b: Spider cocoons and their suspension systems as barriers to generalist and specialist predators. Oecologia 91: 530535.

KASTON, B. J. 1970: Comparative biology of black widow American spiders. Transactions of the San Diego Society of Natural History 16: $33-82$

KNOFLACH, B. \& VAN HARTEN, A. 2006: The one-palped spider genera Tidarren and Echinotheridion in the Old World (Araneae, Theridiidae), with comparative remarks on Tidarren from America. Journal of Natural History 40: 1483-1616.

LASALLE, J. 1994: North American genera of Tetrastichinae (Hymenoptera: Eulophidae). Journal of Natrual History 28: 109236.
LOIÁCONO, M. S. 1973: Notas sobre proctotrupoideos neotropicales I (Hymenoptera). Neotrópica 19: 138-140.

LOTFALIZADEH, H., DELVARE, G. \& RASPLUS, J.-Y. 2007: Phylogenetic analysis of Eurytominae (Chalcidoidea: Eurytomidae) based on morphological characters. Zoological Journal of the Linnean Society 151: 441-510.

MADRIGAL-BRENES, R. \& BARRANTES, G. 2009: Construction and function of the web of Tidarren sisyphoides (Araneae: Theridiidae). Journal of Arachnology 37: 305-311.

MARGARÍA, C. B., LOIÁCONO, M. S. \& GONZAGA, M. O. 2006: Two new species of Baeus (Hymenoptera: Scelionidae) from southeastern Brazil parasitoids of Anelosimus (Araneae: Theridiidae). Zootaxa 1162: 45-52.

MASNER, L. 1995. The proctotrupoid families. In P. E. Hanson, \& I. D. Gauld (eds.), The Hymenoptera of Costa Rica. Oxford, Oxford University Press: 209-246.

MOYA, J., QUESADA, R., BARRANTES, G., EBERHARD, W. G., ESCALANTE, I., ESQUIVEL, C., ROJAS, A., TRIANA, E. \& ARIAS, A. 2010: Egg sac construction by folding dead leaves in Pozonia nigroventris and Micrathena sp. (Araneae: Araneidae). Journal of Arachnology 38: 371-373.

NIELSEN, E. 1932: The biology of spiders. Copenhagen, Levin \& Munksgaard.

PEMBERTON, C. E. \& ROSA, J. S. 1940: Notes on the life history of Baeus californicus Pierce, an egg parasite of the Black Widow spider. Hawaiian Planter's Record 44: 73-80.

PENY, N. D. \& DA COSTA, C. A. 1983: Mantispídeos do Brasil (Neuroptera: Mantispidae). Acta Amazonica 13: 601-687.

REDBORG, K. E. \& MACLEOD, E. G. 1985: The developmental ecology of Mantispa uhleri Banks (Neuroptera: Mantispidae). Illinois Biological Monographs 53: 130 pp.

STEVENS, N. B. \& AUSTIN, A. D. 2007: Systematics, distribution and biology of the Australian 'micro-flea' wasps, Baeus spp. (Hymenoptera: Scelionidae): parasitoids of spider eggs. Zootaxa 1499: $1-45$.

VALERIO, C. E. 1971. Parasitismo en huevos de araña Achaearanea tepidariorum (Koch) en Costa Rica. Revista Biología Tropical 18: 99-106.

VALERIO, C. E. 1975: A unique case of mutualism. American Naturalist 109: 235-238. 